\title{
Social modulation of associative fear learning by pheromone communication
}

\author{
Timothy W. Bredy ${ }^{1,2,4}$ and Mark Barad ${ }^{1-3}$ \\ ${ }^{1}$ Semel Institute for Neuroscience and Human Behavior, UCLA, Los Angeles, California 90095, USA; ${ }^{2}$ Department \\ of Psychiatry and Biobehavioral Sciences, UCLA, Los Angeles, California 90095, USA; ${ }^{3}$ West Los Angeles VA Medical \\ Center, Los Angeles, California 90073, USA
}

\begin{abstract}
Mice communicate through visual, vocal, and olfactory cues that influence innate, nonassociative behavior. We here report that exposure to a recently fear-conditioned familiar mouse impairs acquisition of conditioned fear and facilitates fear extinction, effects mimicked by both an olfactory chemosignal emitted by a recently fear-conditioned familiar mouse and by the putative stress-related anxiogenic pheromone $\beta$-phenylethylamine ( $\beta$-PEA). Together, these findings suggest social modulation of higher-order cognitive processing through pheromone communication and support the concurrent excitor hypothesis of extinction learning.
\end{abstract}

Social communication in mammals has evolved to facilitate reproductive behavior and for protection against environmental threat and predation. Mice communicate information about imminent danger through vocal (Seyfarth and Cheney 2003), visual (Kavaliers et al. 2001; Langford et al. 2006), and odor or pheromone cues (Rottman and Snowdon 1972), each with profound influences on defensive responding. There is also evidence of social empathy in mice (Langford et al. 2006). Mice will sensitize to pain-inducing stimuli simply by observing a conspecific that is currently experiencing pain. Importantly, sensitization occurs only when the conspecific is familiar with the observer (i.e., sibling or cage mate), a clear example of social modulation of an innate behavior. Müller-Velten (1966) provided the first evidence of a functional alarm chemosignal in mice by showing that animals would avoid a pathway in which the odor of a stressed mouse was present. Subsequent studies have shown effects of mammalian olfactory chemosignals on a variety of defensive behaviors such as analgesia, vigilance, and avoidance (Rottman and Snowdon 1972; Mackay-Sim and Laing 1981; Fanselow 1985; Zalaquett and Thiessen 1991). To date, research on social modulation of behavior has focused primarily on observational learning and innate or nonassociative processes. Two recent studies have demonstrated an influence of fear-related chemosignals on associative learning in humans (Chen et al. 2006; Prehn et al. 2006), evidence that supports the hypothesis that social modulation of behavior extends to higher-order cognitive processing.

In the following experiments, we asked whether exposure to a familiar mouse recently fear conditioned or trained for fear extinction would influence associative fear learning in a conspecific. We find that exposure to a recently fear-conditioned mouse impairs acquisition of conditioned fear, while the same experience facilitates the extinction of conditioned fear; effects mimicked by exposure to an olfactory chemosignal emitted from fearconditioned mice and by the putative anxiogenic pheromone, $\beta$ phenylethylamine ( $\beta$-PEA). Interestingly, we find that exposure to a recently extinction-trained mouse results in an inhibition of fear extinction learning, an effect not related to an olfactory chemosignal emitted by a recently extinguished mouse or by exposure to $\beta$-PEA. These data suggest that mice communicate information about their experience, in part through pheromone communica-

\footnotetext{
${ }^{4}$ Corresponding author.
}

E-mail tbredy@mednet.ucla.edu; fax (310) 825-9870.

Article is online at http://www.learnmem.org/cgi/doi/10.1101/lm.1226009. tion, with different effects on associative learning depending on the valence of the task.

\section{Results}

Exposure to a recently fear-conditioned familiar mouse or an olfactory chemosignal from a recently fear-conditioned familiar mouse impairs acquisition of conditioned fear

In order to determine whether learning performance of the observer was specific to the previous experience of fear conditioning in the demonstrator, we compared performance in Social Negative mice with that of a Social Neutral group comprised of observers of mice that had been exposed to Context A with tone presentations but no foot shock. We also wondered what mechanism might underlie the social modulation of associative fear learning. It has been known for many years that mice emit an alarm chemosignal through the release of volatile compounds in their urine and from their preputial glands (Rottman and Snowdon 1972). We therefore added an additional experimental group, Olfactory Negative, which included mice that had been exposed to a cottonball soaked in the urine of familiar fear-conditioned mice. There was a main effect of training $\left(F_{(2,56)}=227.5, P<\right.$ $0.0001, n=8$ /group; Fig. $1 \mathrm{~A}$ ) as all mice showed increased freezing by the third CS-US pairing. There was a main effect of treatment $\left(F_{(3,56)}=7.03, P<0.01\right)$ as Social Negative mice exhibited significantly reduced freezing compared to Naïve and Social Neutral mice (Bonferroni post-hoc analysis; Naïve vs. Social Negative: first, $P<0.05$; second, $P<0.001$; third, $P<0.01$; Social Neutral vs. Social Negative: second, $P<0.001$; third, $P<0.01$ ). Importantly, these effects persisted for $24 \mathrm{~h}$; Social Negative and Olfactory Negative mice showed reduced freezing compared to Naïve mice $\left(F_{(4,35)}=78.69, P<0.0001\right.$; Bonferroni post-hoc analysis Naïve vs. Tone only, Social Negative and Olfactory Negative: $P<0.001$; Social Neutral vs. Social Negative: $P<0.01$; Fig. 1B). These findings indicate that mice communicate fear, in part via olfactory cues in urine, which can affect associative learning by a familiar conspecific.

\section{Exposure to a recently extinction-trained familiar mouse} inhibits extinction learning

We then asked whether social modulation of fear would extend to another associative learning process, fear extinction. Given 
A

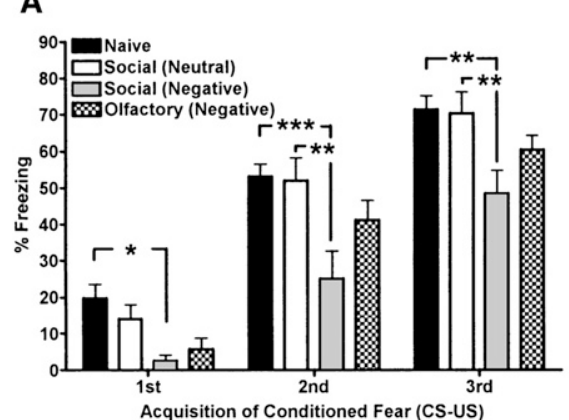

C

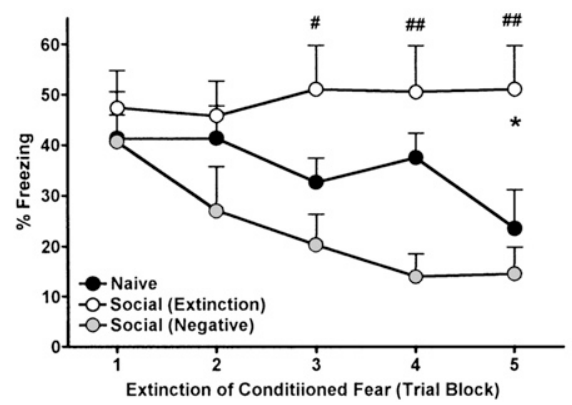

B

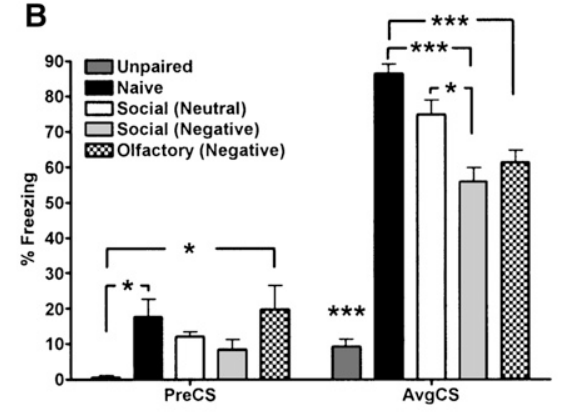

D

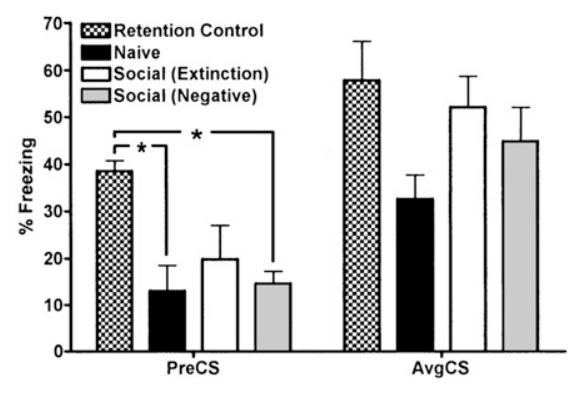

Figure 1. Social modulation of associative fear during $(A)$ acquisition of conditioned fear, $(B)$ retention of fear memory, $(C)$ fear extinction learning ( ${ }^{*} P<0.05$ relative to social extinction; $P<$ $0.001 ; \# P<0.05, \# \# P<0.01$ relative to Social Negative), and $(D)$ retention of extinction memory. Observer mice exposed to recently fear-conditioned mice or an olfactory chemosignal from recently fear-conditioned mice show impaired fear learning. Observer mice exposed to recently extinctiontrained mice show impaired extinction learning. Error bars $\pm \mathrm{SEM} ;\left({ }^{*}\right) P<0.05 ;\left({ }^{* *}\right) P<0.01 ;\left({ }^{* * *}\right) P<$ $0.001 ; n=8-12$ /group.

that there was no difference between Naïve and Social Neutral demonstrator mice in their effect on an observer's ability to extinguish fear, we pooled them into a single control group, called Naïve. Overall, there was a main effect of training $\left(F_{(4,100)}=2.94, P\right.$ $<0.05, n=8-12$ /group) as Naïve and Social Negative mice showed decreased freezing from the first to the fifth trial block (Fig. 1C). There was a main effect of treatment on extinction learning $\left(F_{(2,100)}=5.24, P<0.05\right)$. Relative to extinguished Social Extinction mice, Social Negative mice exhibited less overall freezing indicative of facilitated extinction. At retention test $24 \mathrm{~h}$ later, there was no significant effect on extinction memory. These data on extinction again support the hypothesis that social communication from the demonstrator affects subsequent behavior of the observer mouse, although in this partial extinction protocol, the effect was not strong enough to be seen on the next day (Fig. 1D).

\section{Exposure to an olfactory chemosignal from a recently fear-conditioned familiar mouse facilitates extinction of conditioned fear}

As in Experiment 1, we asked whether exposure to learning-related olfactory cues from the demonstrator mouse would influence extinction of conditioned fear in the observer, in the same way as exposure to a conspecific recently fear-conditioned or extinction trained.
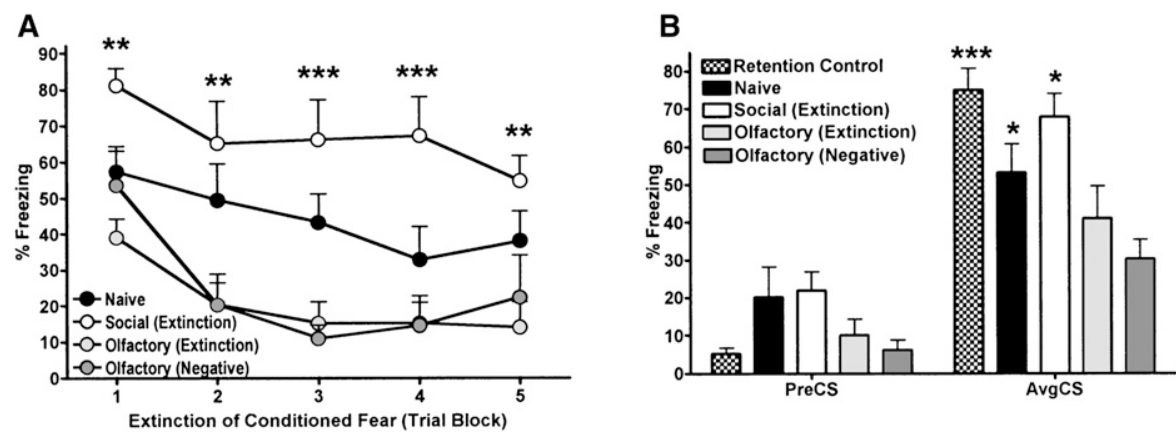

Figure 2. Olfactory Negative chemosignal modulation of associative fear during $(A)$ fear extinction learning and $(B)$ retention of extinction memory. Observer mice exposed to an olfactory chemosignal from either recently fear-conditioned mice or extinction-trained mice show enhanced extinction learning. Error bars \pm SEM; $\left({ }^{*}\right) P<0.05 ;\left({ }^{* *}\right) P<0.01 ;\left({ }^{* * *}\right) P<0.001$ relative to Olfactory Negative; $n=$ 8/group.
There was significant effect of training $\left(F_{(4,112)}=11.55, P<0.0001, n=8 /\right.$ group $)$ as all mice showed decreased freezing from the first to the fifth trial block (Fig. $2 \mathrm{~A})$. There was a significant main effect of treatment as Social Extinction mice showed impaired extinction learning, while Olfactory Negative and Olfactory Extinction mice both showed facilitated extinction learning compared to Naïve mice $\left(F_{(3,112)}=12.49, P<0.0001 ;\right.$ Fig. $\left.2 \mathrm{~A}\right)$. Importantly, relative to Social Extinction mice, Olfactory Extinction mice showed decreasing freezing across all trials (all $P \mathrm{~s}$ $<0.01$ ). When tested for retention $24 \mathrm{~h}$ later, there was a main effect of treatment $\left(F_{(4,35)}=5.71, P<0.01\right)$ as Olfactory Negative showed reduced freezing indicative of enhanced extinction memory relative to Retention Control $(P<$ $0.001)$, Naïve $(P<0.05)$, and Social Extinction $(P<0.05)$ mice (Fig. 2B).

\section{Exposure to $\beta$-PEA, a stress-related} chemosignal, impairs acquisition

\section{of conditioned fear}

We next asked whether volatile $\beta$-PEA, a stress-related chemosignal thought to be an anxiogenic pheromone, would have the same effect as prior fear conditioning in demonstrator mice on the acquisition of conditioned fear in observer mice. There was a main effect of training $\left(F_{(2,42)}=87.11, P<0.0001, n=8 /\right.$ group $)$ as all mice showed increased freezing from the first to the third CS-US pairing. There was a significant main effect of treatment on acquisition of conditioned fear $\left(F_{(2,42)}=7.06, P<0.001\right)$ as $\beta$-PEA-exposed mice showed significantly decreased freezing, while methanol-exposed mice did not freeze differently than naïve mice (Bonferroni posthoc analysis, Naïve vs. $\beta$-PEA, third, $P<0.05$; Methanol vs. $\beta$-PEA, third, $P<0.05$; Fig. 3A). This effect on fear acquisition was also present $24 \mathrm{~h}$ later when mice were tested for retention $\left(F_{(2,21)}=\right.$ $14.41, P<0.0001$; Naïve vs. $\beta$-PEA, $P<0.001$; Methanol vs. $\beta$-PEA, $P<0.01$; Fig. 3B). There was also a main effect of treatment on preCS freezing $\left(F_{(2,21)}=10.65, P<0.001\right.$; Fig. 3B, left $)$, as both 
A

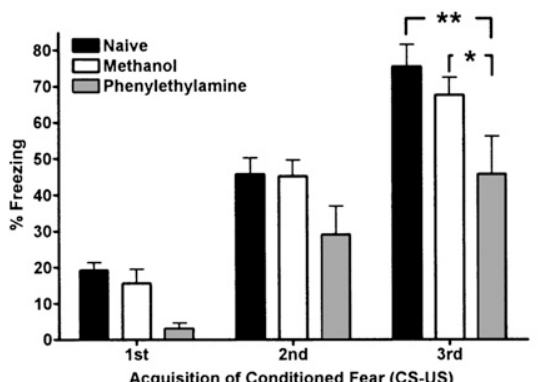

C

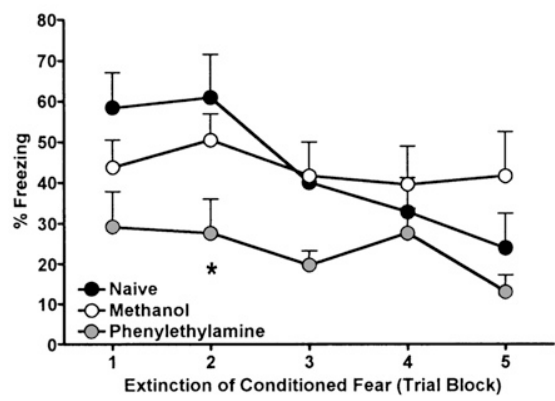

B

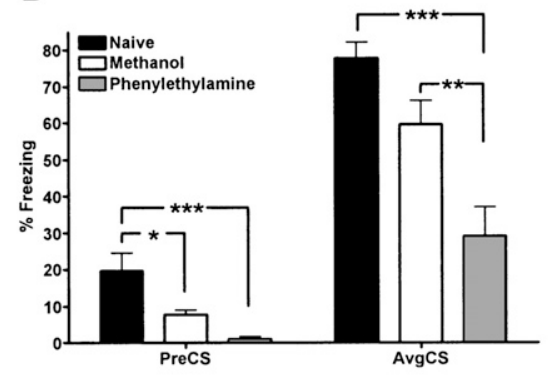

D

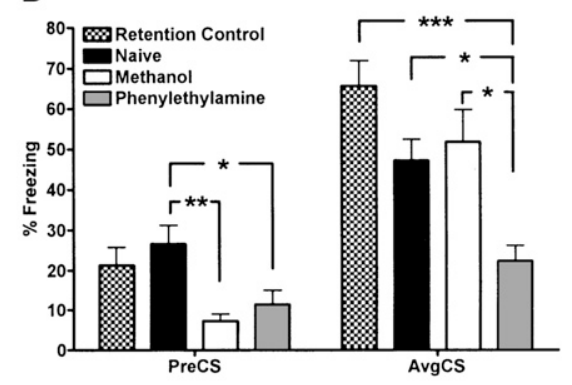

Figure 3. $\beta$-Phenylethylamine modulation of associative fear during $(A)$ acquisition of conditioned fear, $(B)$ retention of fear memory, $(C)$ fear extinction learning, and $(D)$ retention of extinction memory. Observer mice exposed to $\beta$-PEA show impaired fear conditioning, but enhanced extinction learning. Error bars \pm SEM; $\left(^{*}\right) P<0.05 ;\left({ }^{* *}\right) P<0.01 ;\left(^{* * *}\right) P<0.001 ; n=8 /$ group

Methanol $(P<0.05)$ and $\beta$-PEA $(P<0.001)$ mice showed decreased freezing relative to Naïve mice.

\section{Exposure to $\beta$-PEA, a stress-related chemosignal, facilitates extinction of conditioned fear}

We next performed an experiment on the effect of $\beta$-PEA on extinction of conditioned fear. There was a significant main effect of training on extinction learning as all mice showed decreased freezing from the first to the fifth trial block $\left(F_{(4,84)}=4.57, P<0.01\right.$, $n=8$ /group; Fig. 3C). There was a significant main effect of treatment on extinction learning $\left(F_{(4,84)}=4.20, P<0.5\right)$ as prior exposure to $\beta$-PEA significantly decreased freezing relative to Naïve mice during extinction learning, while methanol exposure had no effect (Fig. 3C). This facilitation of fear extinction was still present when mice were tested $24 \mathrm{~h}$ later for retention $\left(F_{(3,28)}=\right.$ 9.03, $P<0.01$; Retention Control vs. $\beta$-PEA: $P<0.001$; Naïve vs. $\beta$ PEA: $P<0.05$; Methanol vs. $\beta$-PEA: $P<0.05$; Fig. $3 D)$. Again, there was also a main effect of treatment on pre-CS freezing $\left(F_{(3,28)}=\right.$ 5.56, $P<0.01$; Fig. 3D, left $)$ as Methanol $(P<0.01)$ and $\beta$-PEA $(P<$ $0.05)$ exposed mice showed decreased freezing relative to Naïve mice.

\section{Exposure to $\beta$-PEA, a stress-related chemosignal, has no effect on locomotor activity but increases pain sensitivity}

To control for nonspecific effects of Social Negative, Olfactory Negative, or $\beta$-PEA on fear learning, we tested for nociception in the hot plate test and novelty-induced locomotor activity. There was no effect on locomotor activity; however, prior exposure to $\beta$-PEA resulted in a significant decrease in latency to paw lift, suggesting increased pain sensitivity $\left(F_{(3,23)}=6.03, P<0.01\right.$, Bonferroni post-hoc analysis; $\beta$-PEA vs. Naïve or Social Negative: $P<0.05$; Fig. 4A).

\section{Discussion}

This study generated three main findings: (1) Exposure to a recently fearconditioned familiar mouse, an olfactory chemosignal from a recently fearconditioned familiar mouse, or a putative anxiogenic pheromone, $\beta$-phenylethylamine ( $\beta$-PEA), impairs acquisition of conditioned fear. (2) The same exposure facilitates extinction learning. (3) Exposure to a recently extinction-trained familiar mouse results in inhibition of extinction learning, an effect not mediated by an olfactory chemosignal emitted from a recently extinguished familiar mouse or by $\beta$-PEA. Similar to the ability of queen pheromone to impair aversive learning without modifying appetitive learning in adult bees (Vergoz et al. 2007) and to context-specific olfactory steroid chemosignal regulation of mood in humans (Jacob and McClintock 2000), our data that suggest fear- or stressrelated social signals emitted by mice may influence associative learning depending on the valence of the task.

\section{Exposure to a recently fear-conditioned familiar mouse or an olfactory chemosignal from} a recently fear-conditioned familiar mouse impairs acquisition of conditioned fear

Acquisition of conditioned fear is potentiated with prior exposure to stress-inducing stimuli. For example, inescapable foot shock or acute restraint stress enhances subsequent acquisition of the conditioned eye blink response and contextual fear (Shors et al. 1992; Cordero et al. 2003; Rau et al. 2005; Rodriguez Manzanares et al. 2005). Additionally, in rats, prior foot shock stress in the demonstrator alters the dynamics of the observer acoustic startle response during contextual fear learning and increases observer social exploration, suggesting significant between-subjects transfer of emotional information (Knapska et al. 2006). Therefore, we were very surprised to find impaired fear conditioning in mice exposed to a recently fear-conditioned familiar mouse or an olfactory chemosignal from a recently fear-conditioned conspecific (Fig. 1A,B).

In addition to direct effects on associative learning, there are at least two potential possibilities for the observed impairment in fear conditioning. First, stress-induced analgesia may account for reduced freezing in response to CS-US presentation during the acquisition of conditioned fear. It has been shown that prior exposure to an olfactory chemosignal from stressed rats elicits an analgesic response (Fanselow 1985). However, we observe reduced freezing upon presentation of the first CS, prior to the first foot shock, a finding that suggests that stress-induced analgesia cannot entirely account for impaired fear learning. Furthermore, prior exposure to Social Negative mice had absolutely no effect on nociception as measured in the hot plate test (Fig. 4A).

Stress-induced locomotor activity, a parameter used to characterize a "proactive" fight-or-flight coping strategy that rodents adopt in response to stress, may also account for the observed impairment of fear learning and, as discussed later, facilitation of extinction (for review, see Koolhaas et al. 2007). Indeed, exposure to an olfactory chemosignal emitted from stressed mice increases 


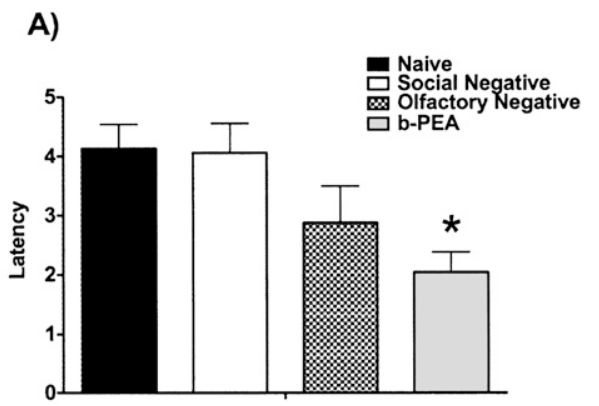

B)

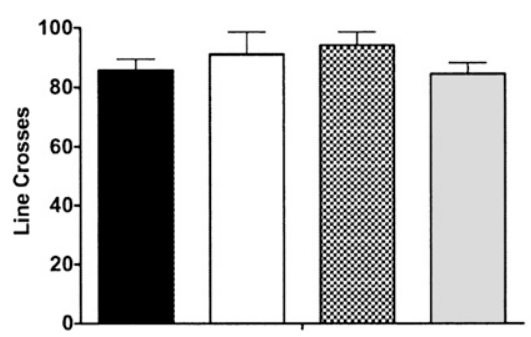

Figure 4. Social Negative, Olfactory Negative, and $\beta$-phenylethylamine modulation of $(A)$ nociception and $(B)$ locomotor activity. Contrary to our expectation, observer mice exposed to $\beta$-PEA show increased pain sensitivity. Error bars $\pm \mathrm{SEM} ;\left(^{*}\right) P<0.05 ; n=6$ /group. There is no effect on locomotor activity.

vigilance and avoidance responses that may also be mediated by increased locomotor activity (Rottman and Snowdon 1972; Zalaquett and Thiessen 1991). However, we did not observe any effect of prior exposure to Social Negative mice, or an olfactory chemosignal from fear-conditioned mice, on novelty-induced locomotor activity (Fig. 4B). The observed effects on learning are therefore not simply the result of a stress-induced influence on coping strategy since observer mice exposed to a recently extinction-trained mouse actually show impaired extinction learning (Fig. 1C,D). A dissociation in the effect of social communication by a demonstrator mouse after fear learning or extinction on subsequent extinction learning in a familiar conspecific suggests effects on associative learning processes not easily explained by changes in coping strategy. These data provide evidence that animals communicate information, in part, through olfactory or pheromone cues.

\section{Exposure to $\beta$-PEA, a stress-related chemosignal, impairs} acquisition of conditioned fear

Several studies demonstrate the presence of increased levels of the biogenic amine $\beta$-PEA in the urine of stressed mice, rats, and humans (Paulos and Tessel 1982; Snoddy et al. 1985; Grimsby et al. 1997). This stress-related compound, initially thought to be a metabolic byproduct of stress-related dopamine release, has a profound influence on fear behavior and defensive responding in rats, mice, and humans when administered systemically (Lapin 1990; Burchett and Hicks 2006). Receptors for $\beta$-PEA are highly expressed throughout the limbic system with the highest levels found within the amygdaloid complex (Borowsky et al. 2001). Thus, $\beta$-PEA is in a perfect position to modulate associative fear learning. Similar to exposure to fear-conditioned mice, exposure to $\beta$-PEA resulted in a profound impairment in the acquisition of conditioned fear accompanied by increased nociception (Figs.
3A,B and 4A). Importantly, the effect of $\beta$-PEA was mediated through olfactory signaling, as with exposure to an olfactory chemosignal emitted from fear-conditioned mice.

Phasic activation of biogenic amine systems is necessary and sufficient for mediating aversive or appetitive olfactory conditioning (Schroll et al. 2006), and highly tuned olfactory receptor neurons are important mediators of innate behaviors. Liberles and Buck discovered a novel class of trace amine receptors (TAAR4) in the main olfactory epithelium that respond with a high degree of specificity to $\beta$-PEA (Liberles and Buck 2006). $\beta$-PEA also activates TAAR1, a trace-amine receptor that directly modulates dopaminergic function and is implicated in psychiatric disorders (Wolinsky et al. 2007; Lindemann et al. 2008; Xie and Miller 2008). There are direct projections from the olfactory bulb to regions of the amygdala that support fear learning (MohedanoMoriano et al. 2007), and the amygdala is highly activated during between-subjects transfer of emotional information (Knapska et al. 2006). $\beta$-PEA is therefore well positioned to directly modulate information exchange about fear or threatening stimuli by olfactory or pheromone signaling.

\section{Exposure to a recently fear-conditioned mouse, an olfactory chemosignal from a recently fear-conditioned mouse, or $\beta$-PEA facilitates the extinction of conditioned fear}

In contrast to the acquisition of conditioned fear, we find that extinction of conditioned fear is enhanced after exposure to a recently fear-conditioned mouse, after exposure to an olfactory chemosignal emitted from a recently fear-conditioned mouse, and after exposure to $\beta$-PEA (Figs. $1 \mathrm{C}, \mathrm{D}, 2 \mathrm{~A}, \mathrm{~B}$, and $3 \mathrm{C}, \mathrm{D}$ ). It has been shown that concurrent activation of the adrenergic system during extinction training enhances long-term memory for fear extinction (Cain et al. 2004). Together, the evidence supports the concurrent excitor hypothesis of Rescorla (2000), which posits that excitation during extinction training serves to enhance longterm memory for this form of inhibitory learning. Exposure to methanol during both the acquisition and extinction of conditioned fear led to reduced pre-CS freezing prior to test in Context B $24 \mathrm{~h}$ later (Fig. 3B,D, left). Given that the reduction in freezing paralleled the effect of $\beta$-PEA, the data suggest an element of novelty-induced learning, which may also contribute to the effect of prior exposure to a fear-conditioned mouse, an olfactory chemosignal from a fear-conditioned mouse, or $\beta$-PEA. However, it is important to point out that methanol was without effect on fear responding to CS in either learning paradigm, which further strengthens the argument for a specific role of $\beta$-PEA in the social modulation of different forms of cue-based associative learning.

\section{Exposure to a recently extinction-trained familiar mouse leads to inhibition of extinction learning}

In contrast to the facilitating effect of exposure to a recently fearconditioned familiar mouse on extinction, exposure to a recently extinction-trained familiar mouse leads to an almost complete blockade of extinction learning (Figs. 1C and 2A). Interestingly, this impairment of fear extinction learning was not related to exposure to an olfactory chemosignal emitted by recently extinguished mice (Fig. 2A), which, presumably, would not have carried the same olfactory signature as an olfactory chemosignal emitted by recently fear-conditioned mice that facilitated extinction learning. However, we cannot rule out the possibility that the olfactory chemosignal was similar for fear-conditioned and fearextinction mice since the early phase of extinction requires reactivation of the original fear memory, which may also elicit a release of fear-related alarm chemosignal in fear-extinction mice. Importantly, the effect is not related to the stress-related pheromone 
$\beta$-PEA. Perhaps some other biogenic amine released by extinctiontrained mice served to modify extinction learning in the observer. For example, the biogenic amine octopamine modulates rewardrelated behavior in insects (Unoki et al. 2006), and receptors specific for octopamine have been characterized in the mouse (Zucchi et al. 2006). Thus, there remains the possibility that extinction-trained mice emit a distinct olfactory chemosignal that is detected by their familiar conspecific.

At this point, the mechanism for this effect remains unknown; however, we propose a second possibility: Extinctiontrained mice might communicate a safety signal through vocal cues that serve to alter expectation of the impending experience in the observer. When the observer mouse is presented with tone CSs in Context $\mathrm{B}$, rather than initiate extinction learning, they instead show increased freezing due to an exaggerated response to the CS, resulting from a violation of their expectation for a safe experience. This pre-exposure effect resembles a phenomenon called "latent inhibition." Latent inhibition is traditionally thought of as a reduction in associative learning in animals that are pre-exposed to the CS relative to those that have not been pre-exposed (Lubow and Moore 1959). Thus, it is possible that we are observing a reduction in the ability to learn a CS-no US relationship after the communication of a putative safety signal from an extinctiontrained conspecific. Future studies will resolve this issue and determine what mode of communication serves to impair extinction learning.

In conclusion, a correlation between learning in Social Negative, Olfactory Negative, and $\beta$-PEA exposed mice suggests a potential role for pheromone communication in social modulation of higher-order cognitive processing. A fear-related olfactory chemosignal can either impair or enhance learning, depending on the valence of the task, and in the case of facilitated extinction, the evidence supports the concurrent excitor hypothesis of extinction learning. Our findings also suggest that social communication occurs after exposure of demonstrators to extinction training, and that this communication may be mediated by a mechanism not only different from that olfactory signal but that also overcomes the olfactory signal from those animals, which has the same valence as that from fear-conditioned demonstrators. These data indicate a complex set of social communications around fear conditioning and its extinction.

\section{Materials and Methods}

\section{Subjects}

Naïve 10-12-wk-old C57BL/6 male mice (Taconic Farms, Germantown, NY) were housed four per cage, maintained on a 12-h light/ dark schedule, and allowed access to food and water ad libitum. Except for routine cage maintenance, mice were left unhandled until $4 \mathrm{~h}$ before training on Day 1 . At this point, pairs of familiar mice were randomly assigned as either demonstrator or observer and pair-housed, two per cage, for the duration of all experiments. Social interaction between one familiar demonstrator and one familiar observer occurred for $30 \mathrm{~min}$ in their homecage. All testing was conducted during the light phase in illuminated testing rooms following protocols approved by the Institutional Animal Care and Use Committee of the University of California, Los Angeles.

\section{Chemical agents}

Cottonballs were soaked with $\beta$-phenylethylamine (Sigma) or methanol (Fisher Scientific) and exposed to observer mice for 35 min prior to behavioral training. Methanol was used as a neutral olfactory stimulus because we routinely use it to clean the apparatus between trials and have never observed any effect on extinction learning.

\section{Conditioning apparatus}

Two contexts (A and B), in separate rooms, were used for all behavioral fear testing. Shuttle box compartments (Med Associates) measuring $20.3 \times 15.9 \times 21.3 \mathrm{~cm}$ served as Context $\mathrm{A}$, and conditioning boxes (Med Associates) measuring $30.5 \times$ $24.1 \times 21 \mathrm{~cm}$ served as Context B. Both contexts have two transparent walls and stainless steel grid floors $(3.2 \mathrm{~mm}$ in diameter, 8-mm centers); however, the grid floors in Context B were covered with flat, white, acrylic inserts to minimize context generalization. Context A was wiped down before testing with $10 \%$ ethanol, and Context B was wiped down with $10 \%$ methanol. Individual videocameras were mounted in the ceiling of each chamber and connected via a quad processor to a standard videocassette recorder and monitor for videotaping and scoring of freezing. Grid floors were connected to a scrambled shock source (Med Associates). Auditory stimuli (Med Associates) were delivered via a speaker in the chamber wall. Delivery of stimuli was controlled with a personal computer and Med-PC software through a SmartCTL Interface System (DIG-716; Med Associates). Background white noise was maintained at $62 \mathrm{~dB}$ throughout behavioral testing.

\section{Experiment 1-behavioral protocol for social modulation of fear conditioning}

Fear conditioning consisted of three pairings (2-min intertrial interval) of a 2-min, 80-dB, white-noise-conditioned stimulus (CS) co-terminating with a 2 -sec, $1.0-\mathrm{mA}$ foot shock in Context A. Naive mice were fear conditioned immediately upon removal from their homecage. Social Neutral mice were fear conditioned after exposure for $35 \mathrm{~min}$ to demonstrator mice that had experienced Context A with tone presentations only. Social Negative mice were fear conditioned after exposure for $35 \mathrm{~min}$ to demonstrator mice that had been previously fear conditioned in Context A. Olfactory Negative mice were fear conditioned after exposure for $35 \mathrm{~min}$ to a cottonball saturated with the urine from familiar conspecific demonstrator mice that had recently been fear conditioned. Tone-only mice were exposed to the apparatus for the same duration as the other mice but with no foot shock. On Day 2, all mice were tested for cued-fear memory with two 2-min CS exposures (2-min ITI) in Context B. Pre-CS freezing was also scored during the 2 min immediately preceding the first test CS.

\section{Experiments 2 and 3-behavioral protocol for social modulation of fear extinction}

On Day 1, fear conditioning was carried out in Context A as described above. Mice were matched into equivalent treatment groups based on freezing during the third training CS and assigned to Naïve, Social Extinction, or Social Negative groups (for Experiment 2), and Naïve, Social Extinction, Olfactory Extinction, or Olfactory Negative groups (for Experiment 3). Observer mice in the Social Extinction group were first exposed for 35 min to demonstrators that had been fear conditioned on Day 1 and extinction trained with 10 nonreinforced CS presentations in Context B on Day 2 (5-sec ITI). Social Extinction mice then received $10 \mathrm{CS}$ extinction training (10 nonreinforced CS presentations are partial extinction training, not enough to generate significant lasting extinction, and are used to detect whether social interactions facilitated extinction memory). Observer mice in the Social Negative group were first exposed for 35 min to demonstrators that had been given three foot shocks $(1.0 \mathrm{~mA})$ in Context $\mathrm{A}$, after which observers received extinction training in Context B. Observer mice in the Olfactory Extinction and Olfactory Negative groups were exposed for 35 min to a cottonball soaked in the urine of recently extinctiontrained or recently fear-conditioned mice, respectively. Retention control mice were exposed to Context B without extinction training. On Day 3, all mice were tested for extinction memory with two 2-min CS exposures (2-min ITI) in Context B. Pre-CS freezing was also scored during the $2 \mathrm{~min}$ immediately preceding the first test CS. 


\section{Experiment 4-behavioral protocol for $\beta$-PEA modulation of fear conditioning}

Fear conditioning consisted of three pairings (2-min intertrial interval) of a 2-min, 80-dB, white-noise-conditioned stimulus (CS) co-terminating with a 2 -sec, $1.0-\mathrm{mA}$ foot shock in Context A. Naïve mice were fear conditioned immediately upon removal from their homecage. Methanol mice were exposed for $35 \mathrm{~min}$ to a cottonball saturated with methanol, after which Methanol mice were fear conditioned as described. Phenylethylamine mice were exposed for $35 \mathrm{~min}$ to a cottonball saturated with $\beta$-PEA, after which Phenylethylamine mice were fear conditioned as described above. On Day 2, all mice were tested for cued-fear memory with two 2-min CS exposures (2-min ITI) in Context B. Pre-CS freezing was also scored during the 2 min immediately preceding the first test CS.

\section{Experiment 5-behavioral protocol for $\beta$-PEA modulation of fear extinction}

On Day 1, fear conditioning was carried out in Context A as described above. Mice were matched into equivalent treatment groups based on freezing during the third training CS and assigned to Naïve, Methanol, or Phenylethylamine groups. Naïve mice received extinction training without other manipulation. Methanol observer mice were exposed for $35 \mathrm{~min}$ to a cottonball saturated with methanol and then extinction trained in Context $\mathrm{B}$ as above. Phenylethylamine observer mice were exposed for 35 min to a cottonball saturated with $\beta$-PEA and then extinction trained in Context B. Retention control mice were simply exposed to Context B without extinction training. On Day 3, all mice were tested for extinction memory with two 2-min CS exposures (2-min ITI) in Context B. Pre-CS freezing was also scored during the 2 min immediately preceding the first test CS.

\section{Data analyses}

Behavioral freezing, the absence of all nonrespiratory movements, was rated during all phases by an experienced investigator blind to subject ID, using a 5-sec instantaneous time sampling technique. The percentage of samples with freezing was calculated for each mouse, and data represent the mean \pm SEM freezing percentages for groups of mice during specified time bins. Total session means and individual CS exposures were analyzed with one-way ANOVA or two-way mixed ANOVA with Bonferroni post-hoc tests where appropriate.

\section{Experiment 6-nociception}

Mice were acclimatized to a hot plate (Columbus Instruments), preheated to $30^{\circ} \mathrm{C}$, two times on each of $2 \mathrm{~d}$ before testing. On the day of testing, mice were exposed to Social Negative, Olfactory Negative, or $\beta-P E A$ as described in Experiments 1 and 4. Mice were tested on a hot plate set to $52^{\circ} \mathrm{C}$. Response latency was determined as the time taken to lick a hind paw or jump. Measurements were taken twice, with at least 10 min between each trial, and averaged. Latencies were analyzed by one-way ANOVA with Bonferroni posthoc tests where appropriate.

\section{Locomotor activity}

A separate group of mice were exposed to Social Negative, Olfactory Negative, or $\beta$-PEA, as described in Experiments 1 and 4. Mice were then placed in a novel environment (apparatus measuring $30.5 \times 24.1 \times 21 \mathrm{~cm}$ ), and locomotor activity was videotaped for $5 \mathrm{~min}$. The number of line crosses was assessed by an observer blind to the identity of the subjects and analyzed by one ANOVA with Bonferroni post-tests where appropriate.

\section{Acknowledgments}

This work was supported in part by grants from the NIMH and the Tennenbaum Family Foundation (to M.B.) and by postdoctoral fellowships from NSERC and CIHR (to T.W.B.). We thank James
McGaugh, Richard Brown, and Terra Branton for their helpful comments on and discussion of this work.

\section{References}

Borowsky, B., Adham, N., Jones, K.A., Raddatz, R., Artymyshyn, R., Ogozalek, K.L., Durkin, M.M., Lakhlani, P.P., Bonini, J.A., Pathirana, S., et al. 2001. Trace amines: Identification of a family of mammalian G protein-coupled receptors. Proc. Natl. Acad. Sci. 98: 8966-8971.

Burchett, S.A. and Hicks, T.P. 2006. The mysterious trace amines: Protean neuromodulators of synaptic transmission in mammalian brain. Prog. Neurobiol. 279: 223-246.

Cain, C.K., Blouin, A.M., and Barad, M. 2004. Adrenergic transmission facilitates extinction of conditional fear in mice. Learn. Mem. 11: 179187.

Chen, D., Katdare, A., and Lucas, N. 2006. Chemosignals of fear enhance cognitive performance in humans. Chem. Senses 31: 415-423.

Cordero, M.I., Venero, C., Kruyt, N.D., and Sandi, C. 2003. Prior exposure to a single stress session facilitates subsequent contextual fear conditioning in rats. Evidence for a role of corticosterone. Horm. Behav. 44: $338-345$.

Fanselow, M.S. 1985. Odors released by stressed rats produce opioid analgesia in unstressed rats. Behav. Neurosci. 99: 589-592.

Grimsby, J., Toth, M., Chen, K., Kumazawa, T., Klaidman, L., Adams, J.D., Karoum, F., Gal, J., and Shih, J.C. 1997. Increased stress response and $\beta$-phenylethylamine in MAOB-deficient mice. Nat. Genet. 17: 206210 .

Jacob, S. and McClintock, M.K. 2000. Psychological state and mood effects of steroidal chemosignals in women and men. Horm. Behav. 37: 57-78.

Kavaliers, M., Choleris, E., and Colwell, D.D. 2001. Learning from others to cope with biting flies: Social learning of fear-induced conditioned analgesia and active avoidance. Behav. Neurosci. 115: 661-674.

Knapska, E., Nikolaev, E., Boguszewski, P., Walasek, G., Blaszczyk, J., Kaczmarek, L., and Werka, T. 2006. Between-subject transfer of emotional information evokes specific pattern of amygdala activation. Proc. Natl. Acad. Sci. 103: 3858-3862.

Koolhaas, J.M., de Boer, S.F., Buwalda, B., and van Reenen, K. 2007. Individual variation in coping with stress: A multidimensional approach of ultimate and proximate mechanisms. Brain Behav. Evol. 70: $218-226$.

Langford, D.J., Crager, S.E., Shehzad, Z., Smith, S.B., Sotocinal, S.G., Levenstadt, J.S., Chanda, M.L., Levitin, D.J., and Mogil, J.S. 2006. Social modulation of pain as evidence for empathy in mice. Science 312: 1967-1970.

Lapin, I.P. 1990. $\beta$-Phenylethylamine (PEA): An endogenous anxiogen? Three series of experimental data. Biol. Psychiatry 28: 997-1003.

Liberles, S.D. and Buck, L.B. 2006. A second class of chemosensory receptors in the olfactory epithelium. Nature 442: 645-650.

Lindemann, L., Meyer, C.A., Jeanneau, K., Bradaia, A., Ozmen, L., Bluethmann, H., Bettler, B., Wettstein, J.G., Borroni, E., Moreau, J.L., et al. 2008. Trace amine-associated receptor 1 modulates dopaminergic activity. J. Pharmacol. Exp. Ther. 324: 948-956.

Lubow, R.E. and Moore, A.U. 1959. Latent inhibition: The effect of nonreinforced pre-exposure to the conditional stimulus. J. Comp. Physiol. Psychol. 52: 415-419.

Mackay-Sim, A. and Laing, D.G. 1981. Rats' responses to blood and body odors of stressed and non-stressed conspecifics. Physiol. Behav. 27: 503-510.

Mohedano-Moriano, A., Pro-Sistiaga, P., Ubeda-Banon, I., Crespo, C., Insausti, R., and Martinez-Marcos, A. 2007. Segregated pathways to the vomeronasal amygdala: Differential projections from the anterior and posterior divisions of the accessory olfactory bulb. Eur. J. Neurosci. 25: 2065-2080.

Müller-Velten, H.G. 1966. Uber den angstgeruch bei der hausmaus. Z. Verge Physiol. 52: 401-429.

Paulos, M.A. and Tessel, R.E. 1982. Excretion of $\beta$-phenethylamine is elevated in humans after profound stress. Science 215: 1127-1129.

Prehn, A., Ohrt, A., Sojka, B., Ferstl, R., and Pause, B.M. 2006. Chemosensory anxiety signals augment the startle reflex in humans. Neurosci. Lett. 394: 127-130.

Rau, V., DeCola, J.P., and Fanselow, M.S. 2005. Stress-induced enhancement of fear learning: An animal model of posttraumatic stress disorder. Neurosci. Biobehav. Rev. 29: 1207-1223.

Rescorla, R.A. 2000. Extinction can be enhanced by a concurrent excitor. J. Exp. Psychol. Anim. Behav. Process. 26: 251-260.

Rodriguez Manzanares, P.A., Isoardi, N.A., Carrer, H.F., and Molina, V.A. 2005. Previous stress facilitates fear memory, attenuates GABAergic inhibition, and increases synaptic plasticity in the rat basolateral amygdala. J. Neurosci. 25: 8725-8734.

Rottman, S.J. and Snowdon, C.T. 1972. Demonstration and analysis of an alarm pheromone in mice. J. Comp. Physiol. Psychol. 81: 483-490. 
Schroll, C., Riemensperger, T., Bucher, D., Ehmer, J., Voller, T., Erbguth, K., Gerber, B., Hendel, T., Nagel, G., Buchner, E., et al. 2006. Light-induced activation of distinct modulatory neurons triggers appetitive or aversive learning in Drosophila larvae. Curr. Biol. 16: 1741-1747.

Seyfarth, R.M. and Cheney, D.L. 2003. Signalers and receivers in animal communication. Annu. Rev. Psychol. 54: 145-173.

Shors, T.J., Weiss, C., and Thompson, R.F. 1992. Stress-induced facilitation of classical conditioning. Science 257: 537-539.

Snoddy, A.M., Heckathorn, D., and Tessel, R.E. 1985. Cold-restraint stress and olfactory endogenous $\beta$-phenylethylamine excretion in rats. Pharmacol. Biochem. Behav. 22: 497-500.

Unoki, S., Matsumoto, Y., and Mizunami, M. 2006. Roles of octopaminergic and dopaminergic neurons in mediating reward and punishment signals in insect visual learning. Eur. J. Neurosci. 24: 2031-2038.

Vergoz, V., Schreurs, H.A., and Mercer, A.R. 2007. Queen pheromone blocks aversive learning in young worker bees. Science 317: 384-386.
Wolinsky, T.D., Swanson, C.J., Smith, K.E., Zhong, H., Borowsky, B., Seeman, P., Branchek, T., and Gerald, C.P. 2007. The trace amine 1 receptor knockout mouse: An animal model with relevance to schizophrenia. Genes Brain Behav. 6: 628-639.

Xie, Z. and Miller, G.M. 2008. $\beta$-Phenylethylamine alters monoamine transporter function via trace amine-associated receptor 1: Implication for modulatory roles of trace amines in brain. J. Pharmacol. Exp. Ther. 325: 617-628.

Zalaquett, C. and Thiessen, D. 1991. The effects of odors from stressed mice on conspecific behavior. Physiol. Behav. 50: 221-227.

Zucchi, R., Chiellini, G., Scanlan, T.S., and Grandy, D.K. 2006. Trace amine-associated receptors and their ligands. Br. J. Pharmacol. 149: 967-978.

Received September 16, 2008; accepted in revised form October 16, 2008. 


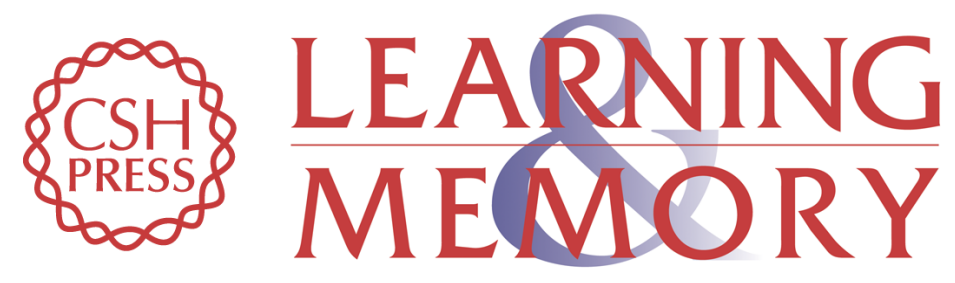

\section{Social modulation of associative fear learning by pheromone communication}

Timothy W. Bredy and Mark Barad

Learn. Mem. 2009, 16:

Access the most recent version at doi:10.1101//m.1226009

References This article cites 35 articles, 10 of which can be accessed free at: http://learnmem.cshlp.org/content/16/1/12.full.htmI\#ref-list-1

License

Email Alerting Receive free email alerts when new articles cite this article - sign up in the box at the Service top right corner of the article or click here. 